\title{
PENGARUH KOMPOSISI PEREKAT TEPUNG PADA BIOBRIKET LIMBAH BAGLOG JAMUR
}

\author{
Widodo Hadi Prabowo ${ }^{12}$, Muhammad Viki Lutfiana ${ }^{22}$, Rosid ${ }^{32}$, Muhammad Burhanuddin \\ $\underline{\text { Ubaidillah }}^{4)}$ \\ ${ }^{1}$ Teknik Elektro, Fakultas Teknik, Universitas Muhammadiyah Surakarta. \\ email:D400140012@student.ums.ac.id \\ ${ }^{2}$ Teknik Elektro, Fakultas Teknik, Universitas Muhammadiyah Surakarta. \\ email:D400140007@student.ums.ac.id \\ ${ }^{3}$ Teknik Elektro, Fakultas Teknik, Universitas Muhammadiyah Surakarta. \\ email:D400140123@student.ums.ac.id \\ ${ }^{4}$ Teknik Elektro, Fakultas Teknik, Universitas Muhammadiyah Surakarta. \\ email:D400150099@student.ums.ac.id
}

\begin{abstract}
Energy derived from biomass such as baglog waste that has been disposed or not utilized, is a waste that can be converted into alternative energy sources of fossil fuel. In this study waste baglog mushrooms are used as fuel by turning the waste into a composite comparison biobriket comparison $A(1: 1: 1)$ namely with the composition of the starch 250 grams of the waste baglog 250 grams and water $250 \mathrm{ml}$, B ratio (1: 2: 2) namely with the composition of the starch 250 grams of the waste baglog 500 grams and water $500 \mathrm{ml}, \mathrm{C}$ ratio (1: 3: 3) namely with the composition of the starch 250 grams of the waste baglog 1000 grams and water $1000 \mathrm{ml}$, The purpose of this research is to assess the rate of burning, calorific value, ash content, steam of water content, carbon content and drop test bio-briquette. The results of the research obtained the best value of calori, water content, carbon content and the content of the evaporating agent in A (1: 1: 1) biobriket of 4065,69 $\mathrm{kal} / \mathrm{g}, 5 \%$ and 17,1\%, for the best ash content found in sample B (1:2:2) in the amount of 4.8\%. The method used in this study baglog the destruction of the rest Baglog and drying, making flour starch, mixing starch with baglog waste, briquette pressing then dried
\end{abstract}

Keyword: Baglog waste, biobriquett, fossil fuel, oyster mushroom

\begin{abstract}
Abstrak-
Energi yang berasal dari biomassa misalnya limbah baglogyang selama ini dibuang atau tidak dimanfaatkan, merupakan limbah yang dapat dikonfersi menjadi sumber energi alternatif penggant bahan bakar fosil Dalam penelitian ini limbah baglog jamur dimanfaatkan sebagai bahan bakar dengan cara mengubah limbah tersebut menjadi biobriket perbandingan komposisi yaitu perbandingan A (1:1:1) yaitu dengan komposisi tepung kanji 250 gram limbah baglog 250 gram dan air $250 \mathrm{ml}$, perbandingan B (1:2:2) yaitu dengan komposisi tepung kanji 250 gram limbah baglog 500 gram dan air $500 \mathrm{ml}$, perbandingan C (1:3:3) yaitu dengan komposisi tepung kanji 250 gram limbah baglog 1000 gram dan air $1000 \mathrm{ml}$. Tujuan penelitian ini dilakukan untuk pengkajian laju pembakaran, nilai kalor, kadar abu, kadar air, kadar zat yang menguap, kadar karbon dan tes jatuh biobriket. Hasil penelitian memperoleh nilai kalor, kadar air, kadar karbon dan kadar zat yang menguap terdapat pada biobriket sampel A (1:1:1) sebesar 4065,69 kal/g, 5\%, 17,1\%, dan 71,4 \% untuk kadar abu terbaik terdapat pada sampel B (1:2:2) sebesar 4,8 \%. Metode yang digunakan dalam penelitian ini baglog tersebut penghancuran sisa baglog dan pengeringan, membuat adoanan tepung kanji, pencampuran tepung kanji dengan limbah baglog, pengepresan biobriket kemudian dikeringkan
\end{abstract}

Kata kunci: Limbah baglog, biobriket, bahan bakar fosil, jamur tiram

\section{PENDAHULUAN}

Kebutuhan energi manusia dari waktu kewaktu semakin meningkat seiring dengan bertambahnya penduduk dan teknologi.sehingga menyebabkan kelangkaan energi dan meningkatnya harga minyak bumi didunia. Demikian pula pemerintah Indonesia mengambil langkah untuk menetapkan kenaikan harga bahan bakar minyak (BBM) dan gas lpg. Agar beban masyarakat lebih ringan maka pemerintah menghimbau agar 
dapat memanfaatkan bioenergi yang ada.

Bioenergi adalah energi yang berasal

dari biomassa.Sedangkan pengertian dari biomassa adalah jumlah bahan hidup yang terdapat di dalam satu atau beberapa jenis organisme yang berada di dalam habitat tertentu.Biomasa pada umumnya dinyatakan dalam berat kering organisme persatuan luas habitat. Biomasa adalah salah satu sumberdaya hayati, merupakan energi matahari yang telah ditransformasi menjadi energi kimia oleh tumbuhan berhijau daun.

Kegiatan dibidang pertanian banyak menghasilkan limbah yaitu limbah padat, cair dan gas.Selama ini limbah yang dihasilkan oleh petani belum dimanfaatkan secara optimal, padahal limbah tersebut dapat dimanfaatkan sebagai energi alternatif ataupun produk sampingan yang bernilai ekonomis, sehingga petani memperoleh nilai tambah dari hasil limbah pertanian.Salah satunya pembuatan biobriket dari limbah baglog jamur tiram.Biobriket dari limbah baglog jamur tiram yang dihasilkan dapat menjadi produk yang mempunyai nilai ekonomis.

Biobriket dari limbah baglog jamur tirammampumengubahlimbah pertanian menjadi bahan bakar dengan efisiensi konversi cukup baik. Limbah baglog dari jamur tiram yang sudah tidak produktif jika tidak dimanfaatkan akan menjadi sampah yang menumpuk dan mengotori lingkungan, limbah baglog tersebut dapat dimanfaatkan antara lain dibuat sebagai bahan bakar alternatif pengganti bahan bakar fosil yaitu biobriket.

Tujuan penelitian ini adalah untuk mengetahui cara pembuatan biobriket dari limbah baglog jamur tiram, mengetahui karakteristik biobriket tersebut dan sebagai alternatif bahan bakr yang ekonomis.

\section{METODE}

Kegiatan penelitian dilaksanakan pada bulan maret-juni 2017.Tempat pelaksanakan di Laboratorium Kantor BPSMB Surakarta.

Alat yang dipergunakan dalam penelitian alat pengepres ukuran, tong drum, kuali, kompor, pengaduk kayu, pralon diameter $4 \mathrm{~cm}$, tinggi 5 $\mathrm{cm}$ lubang tengah $0,5 \mathrm{~cm}$, timbangan analog, kalorimeter, oven, cawan, tanur. Bahan yang digunakan untuk pembuatan biobriket adalah limbah baglog jamur tiram, korek api, tepung kanji, air, minyak tanah, plastik

\section{Prosedur Penelitian}

\section{a. Proses Pembuatan Biobriket}

Melakukan pengupasan plastik pada limbah baglog yang terbungkus plastik dan limbah baglog tersebut yang menggumpal dihancurkan agar menjadi rata menjadi serpihan serbuk, kemudian disaring dengan ukuran 60 mesh setelah itu tahap pengeringan, pengeringan ini bertujuan untuk menghilangkan lendir dan air menguap, pengeringan tersebut membutuhkan waktu 3-4 hari, baglog yang seudah kering warnanya akan tampak muda, kemudian membuat biobriket dengan komposisi limbah baglog yang sudah kering, tepung kanji, air mendidihdengan perbandingan antara lain :

1) Biobriket $A$ dengan perbandingan 1:1:1 yaitu dengan komposisi tepung kanji 250 gram, limbah baglog 250 gram, air hangat $250 \mathrm{ml}$

2) Biobriket B dengan perbandingan 1:2:2 yaitu dengan komposisi tepung kanji 250 gram, limbah baglog 50 gram dan air hangat $500 \mathrm{ml}$

3) Biobriket $C$ dengan perbandingan 1:3:3 yaitu 
dengan komposisi tepung kanji 250 gram, limbah baglog 1000 gram, air hangat $1000 \mathrm{ml}$ dengan pencampuran tepung kanjiyang sudah diberi air hangatyaitu limbah baglog yang sudah dikeringkan dan diaduk hingga rata kemudian mencetak adonan dan dipres dengan tekanan $50 \mathrm{~kg} / \mathrm{cm}^{2}$ biobriket hingga padat kemudian dikeluarkan dari cetakan dan dikeringkan selama 4-6 hari, setelah padat dan kering biobriket siap digunakan.

\section{b. Uji Karakteristik Biobriket}

Bahan bakar padat memiliki karakteristik dasar sebagai berikut

1) Nilai Kalor

Nilai kalor bahan bakar adalah jumlah satuan panasyang dihasilkan persatuan bobot dari proses pembakaran cukup oksigen dari suatu bahan yang mudah terbakar. Nilai kalor yang diperoleh melalui oksygen bomb calorimeter dengan medel PAAR 1755 EF dengan persamaan sebagai berikut

$$
\mathrm{HHV}=\frac{(\Delta T X E E V)-\left(e_{1}-e_{2}\right)}{\mathrm{m}}-e_{s}(1)
$$

Dimana,

$$
\begin{aligned}
\mathrm{HHV}= & \text { Highest heating Value } \\
& (\text { kal/gram) } \\
\Delta \mathrm{T}= & \text { kenaikan suhu pemba- } \\
& \text { karan di dalam bom } \\
& \text { kalori meter }\left({ }^{\circ} \mathrm{C}\right) \\
\mathrm{EEV}= & \text { energi ekivalen saat } \\
& \text { terjadi pembakaran (kal/ } \\
& \left.{ }^{\circ} \mathrm{C}\right) \\
= & \text { koreksi panas karena } \\
& \text { pembentukan asam }(\mathrm{kal})
\end{aligned}
$$

$$
\begin{aligned}
\mathrm{e}_{2}= & \text { koreksi panas pemba- } \\
& \text { karan dari kawat } \\
& \text { pembakar }(\mathrm{kal}) \\
= & \text { koreksi sulphur yang } \\
& \text { ada dalam bahan bakar } \\
\mathrm{e}_{\mathrm{s}} & (\mathrm{kal} / \mathrm{g}) \\
\mathrm{m} \quad & \text { berat contoh }(\mathrm{g})
\end{aligned}
$$

2) Kadar Air

Prosedur pengukuran kadar air dengan menggunakan oven dan timbangan analog. Contoh sampel uji ditimbang sebanyak 2 gram, kemudian dimasukkan dalam oven 105-110 selama waktu 1 jam.Setelah dipanaskan dari oven kemudian ditimbang lagi. Perhitungan kadar presentase kadar air yang terkandung dalam biobriket tersebut dengan menggunakan standart ASTM D-3173-03 dengan persamaan sebagai berikut

Kadar air $(\%)=$

$$
\frac{\mathrm{G}_{0}-\mathrm{G}_{1}}{\mathrm{G}_{0}} \times 100 \%
$$

Dimana,

$\mathrm{G}^{0}=$ berat contoh sampel sebelum dikeringkan (gr)

$G_{1}=$ berat contoh sampel sesudah dikeringkan dengan temperatur105-110 (gr)

3) Kadar Abu

Kadar abu pengujian dengan menggunakan cawan, tanur dan timbangan analog, untuk mendapatkan nilai kadar abu maka diperlukan perhitungan dengan standar ASTM D-3173-03 sebagai berikut

Kadar abu $(\%)=$

$$
\frac{\mathrm{C}}{A} \times 100 \%(3)
$$


Dimana,

$\mathrm{C}=$ berat abu (gr)

$\mathrm{A}=$ berat bahan sebelum pengabuan (gr)

4) Kadar zat yang menguap (Volatile Matter)

Penentuan zat mudah menguap adalah contoh uji \pm 5 gr setelah diukur berat awal, dimasukkan kedalam cawan porselin dan ditanurkan dengan suhu $900^{\circ} \mathrm{C}$. Contoh uji didinginkan di dalam tanur, setelah dingin tidak ada cuplikan putih (abu), contoh uji dimasukkan kedalam desikator, setelah 1 jam ditimbang sebagai berat (dikurangi berat cawan). Prosedur perhitungan kadar zat yang menguap menggunakan standar ASTM D-3173-03 dengan rumus

Volatile Matter, $\%=$

$$
\frac{E-D}{E} \times 100 \%
$$

Dimana:

$\mathrm{E}=$ berat contoh sampel sebelum dikeringkan (gr)

$\mathrm{D}=$ berat contoh sampel sesudah dikeringkan dengan temperature 900 (gr)

5) Kadar Karbon Terikat (Fixed Carbon)

Kandungan karbon terikat (fixed carbon), yaitu komponen yang bila terbakar tidak membentuk gas yaitu karbon tetap yang terdapat pada bahan bakar padat berupa biobriket. Analisa kadar karbon terikat dapat menggunakan persamaan

$$
\begin{gathered}
\mathrm{FC}=100 \%-(\mathrm{VM}+\text { Kadar air }+ \\
\text { Kadar abu }) \%(5)
\end{gathered}
$$

Dimana,

FC =Fixed Carbon

$\mathrm{VM}=$ Volatile Matter

6) Drop Test

Drip test dilakukan untuk menguji ketahanan biobriket dengan benturan pada permukaan keras dan datar ketika dijatuhkan dari ketinggian 2 meter. Prosedur perhitungan drop test biobriket dengan menggunakan standar ASTM D 440-86 R02 dengan rumus

Drop test

$$
\%=\frac{A-B}{A} \times 100 \%(6)
$$

Dimana,

$\mathrm{A}=$ Berat biobriket sebelum dijatuhkan (gram)

$\mathrm{B}=$ Berat biobriket setelah dijatuhkan (gram)

7) Laju pembakaran

Untuk mendapatkan laju pembakaran sesaat $(m)$ dapat menggunakan rumus,

$$
m=\frac{\Delta \mathrm{m}}{\Delta \mathrm{t}}(7)
$$

dimana :

$\Delta \mathrm{m}=$ laju pengurangan massa $(\mathrm{g})$ $\Delta \mathrm{t}=$ waktu (s).

\section{HASIL DAN PEMNBAHASAN}

Dari hasil uji karakteristik bahan perekat tepung kanji, air mendidih dan tepung kanji dengan perbandingan A (1:1:1), perbandingan B (1:2:2), perbandingan $C$ (1:3:3). Ukuran biobriket 
tersebut diameter $4 \mathrm{~cm}$, tinggi $5 \mathrm{~cm}$ lubang tengah $0,5 \mathrm{~cm}$ seperti pada gambar 1 .

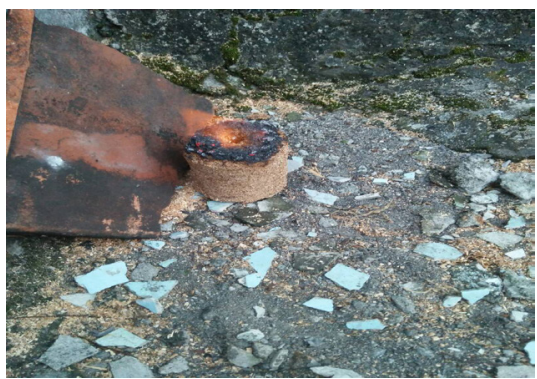

Gambar 1. Biobriket dari limbah baglog jamur

1. Pengaruh Perekat Terhadap Nilai Kalor

Tabel 1. Hasil Pengujian Nilai Kalor

\begin{tabular}{ccc}
\hline Sampel & $\begin{array}{c}\text { Nilai Kalor } \\
(\mathbf{k a l} / \mathrm{g})\end{array}$ & $\begin{array}{c}\text { SNI pada } \\
\text { Arang Kayu }\end{array}$ \\
\hline A (1:1:1) & 4065,69 & \\
B (1:2:2) & 4004,32 & Min 5000 \\
C (1:3:3) & 3904,10 & \\
\hline
\end{tabular}

Nilai kalor dapat diketahui dengan menggunakan bomb calorimeter, dan memperoleh hasil seperti pada Tabel 1 .

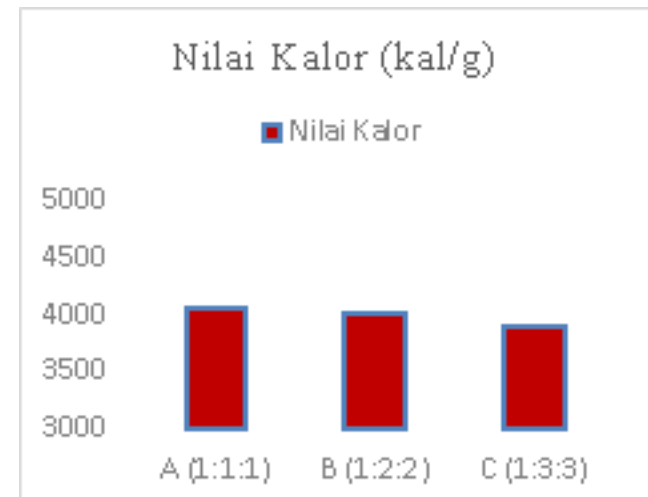

Gambar 1. Grafik perbandingan komposisi pada biobriket terhadap nilai kalor

\section{Pengaruh Perekat Terhadap Kadar Air}

Tabel 2. Hasil Pengujian Kadar Air

\begin{tabular}{ccc}
\hline Sampel & $\begin{array}{c}\text { Kadar Air } \\
(\mathbf{\%})\end{array}$ & $\begin{array}{c}\text { SNI pada } \\
\text { Arang Kayu }\end{array}$ \\
\hline A (1:1:1) & 5 & \\
B (1:2:2) & 6,2 & Max 8 \\
C (1:3:3) & 8,3 & \\
\hline
\end{tabular}

Dari hasi pengujian kadar air diperoleh kadar air terendah yaiti 5\% pada sampel A (1:1:1), kadar air tertinggi pada sampel C (1:3:3) yaitu 8,3\%. Pada Grafik 2 dapat dilihat pengaruh variasi komposisi terhadap kadar air yang dihasilkan. Kenaikan komposisi ranting pada briket akan berpengaruh terhadap besar kadar airnya. Sehingga dari data tersebut komposisi terbaik menurut kadar airnya adalah variasi biobriket $\mathrm{A}$ (1:1:1) dengan kadar air 5\%.

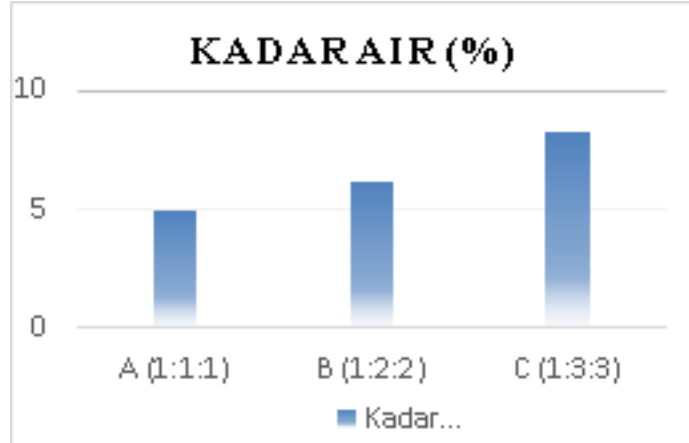

Gambar 2. Grafik perbandingan komposisi pada biobriket terhadap kadar air 
3. Pengaruh Perekat Terhadap Kadar Zat yang Menguap

Tabel 3. Hasil Pengujian Kadar Zat yang Menguap

\begin{tabular}{ccc}
\hline Sampel & $\begin{array}{c}\text { Kadar Zat yang } \\
\text { Menguap (\%) }\end{array}$ & $\begin{array}{c}\text { SNI pada } \\
\text { Arang Kayu }\end{array}$ \\
\hline A (1:1:1) & 71,4 & \\
B (1:2:2) & 72,5 & Max 15 \\
C (1:3:3) & 74 & \\
\hline
\end{tabular}

Dari tabel diatas pada semua komposisi sampel biobriket tidak termasuk SNI, karena kadar zat yang menguap tinggi maka asap yang keluar pada saat pembakaran akan tinggi.

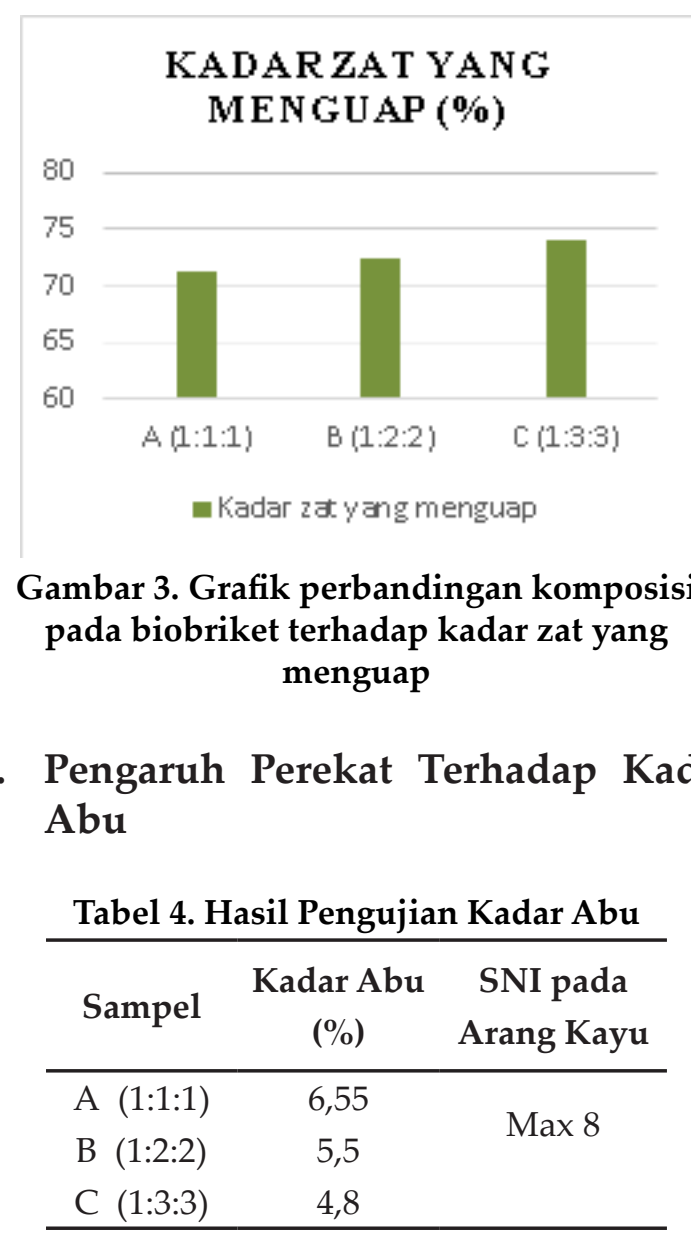

Kandungan Abu yang tinggi dapat menurunkan nilai kalor biobriket limbah baglog, sehingga kualitas biobriket tersebut menurun. Kadar abu tertinggi terdapat pada sampel A (1:1:1) yaitu 6,55 dan kadar abu terendah terdapat pada sampel C (1:2:2) yaitu sebesar 4,8. Kadar abu pada semua sampel sudah termasuk SNI.

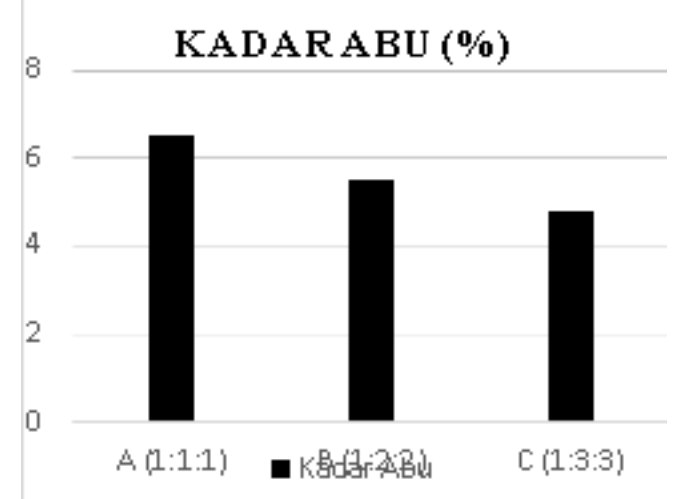

Gambar 4. Grafik perbandingan komposisi pada biobriket terhadap kadar abu

\section{Pengaruh Perekat Terhadap Kadar} Karbon

Tabel 5. Hasil Pengujian Kadar Karbon

\begin{tabular}{ccc}
\hline Sampel & $\begin{array}{c}\text { Kadar } \\
\text { Karbon (\%) }\end{array}$ & $\begin{array}{c}\text { SNI pada } \\
\text { Arang Kayu }\end{array}$ \\
\hline A $(1: 1: 1)$ & 17,1 & \\
B $(1: 2: 2)$ & 14 & Min 77 \\
C (1:3:3) & 9 & \\
\hline
\end{tabular}

Keberadaan kadar karbon didalam biobriket limbah baglog dipengaruhi oleh nilai kadar abu dan kadar zat yang menguap. Kadarnya akan bernilai tinggi apabila kadar abu dan kadr zat yang menguap rendah. Pada tabel 5 menunjukan bahwa semua sampel tida termasuk SNI. 


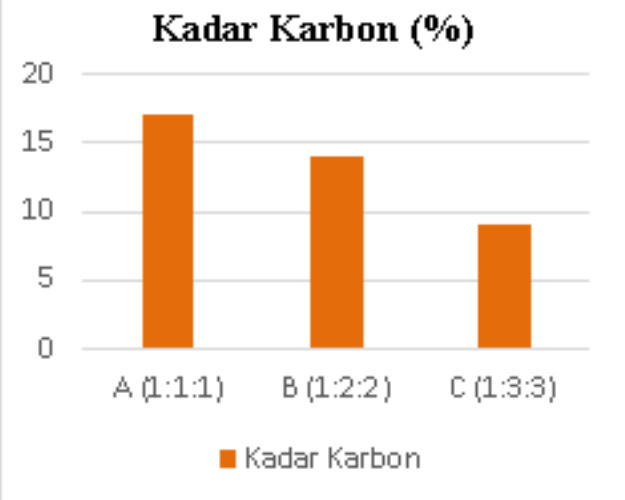

Gambar 5. Grafik perbandingan komposisi pada biobriket terhadap kadar karbon

\section{KESIMPULAN}

Pada biobriket limbah baglog dengan karakteristik terbaik dengan sampel A (1:1:1) yaitu dengan komposisi tepung kanji sebesar 250 gram, limbah baglog 250 gram dan air hangat $250 \mathrm{ml}$ dimana nilai kalor tersebut sebesar 4065,69 $\mathrm{kal} / \mathrm{g}$ kualitas biobriket akan meningkat seiring bertambahnya bahan perekat karena bahan perekat memiliki sifat dapat meningkatkan nilai kalor karena mengandung unsur $\mathrm{C}$ dan tidak melalui proses karbonisasi sehingga nilai kalor tersebut tidak memenuhi standar, kadar air sebesar 5\%, kadar karbon 17,1\% dan kadar zat yang menguap sebesar $71,4 \%$ - pada kadar abu terbaik terdapat pada sampel C (1:3:3) sebesar 4,8\% karena kadar abu yang rendah akan menaikkan nilai kalor pada biobriket. Dari lima analisa yang telah dilakukan terdapat beberapa yang tidak memenuhi standar SNI. Jadi dapat disimpulkan bahawa limbah baglog kurang layak dijadikan bahan bakar biobriket.

\section{UCAPAN TERIMA KASIH}

Terima kasih kepada petani jamur adik viki di desa kutowinangun kecamatan tingkir kota salatiga yang telah memberikan limbah baglog dan kantor BPSMB surakarata yang telah membantu dalam pengujian biobriket.
DAFTAR PUSTAKA

Departemen Energi dan Sumber Daya Mineral (DESDM). (2004). Statistik Energi Indonesia

Earl, D.E., 1974. A report on Corcoal, AndreMeyer Researc Fellow.FAO. Rome.

Haygreen, J.G dkk. 1989. Hasil Hutan dan Ilmu Kayu Semua Pengantar. Diterjemahkan oleh Sutjipto A. Hadikusumo. Gajah Mada University Press. Yogyakarta.

Hendra, D. 1999. Bahan Baku Pembuatan Arang dan Briket Arang. Litbang Hutan.Gunung Batu. Bogor.

Sulistyanto. 2006. Karakteristik Pembakaran Biobriket Campuran Batubaradan Sabut Kelapa. Universitas Muhammadiyah Surakarta, Surakarta. Hal. 45-52

Sani, Hardy Rakhman. 2009. Pembuatan Briket Arang dari Campuran Kulit Kacang Cabang dan Ranting Pohon Sengon serta Sebetan Bambu. Departemen Hasil Hutan Fakultas Kehutanan Institut Pertanian Bogor, Bogor.

Masnun."Teknologi Pembuatan Biobriket dari Limbah Baglog." http://bppjambi.info/newspopup. asp?id=739. Diakses pada tanggal 15 Oktober 2016

Satmoko. 2013. Pengaruh Variasi Temperatur Cetakan Terhadap Karakteristik Briket Kayu Sanggon Pada Tekanan Kompagsi 6000 Psig. Skripsi. Fakultas Teknik Universitas Negeri Semarang, Semarang.

Pane, E. 2015. Pengaruh Konsentrasi Perekat Tepung Tapioka dan Penambahan Kapur Dalam Pembuatan Briket Arang Berbahan Baku Pelepah Aren (Arenga pinnata). Jurnal Teknik Kimia USU. 4 (2) : 32-38. 